\title{
OPTIMIZATION OF TRACTOR OPERATION LEVEL
}

\author{
Ilgiz Galiev ${ }^{1}$, Camill Khafizov ${ }^{1}$, Engel Galimov ${ }^{2}$, Rail Khusainov ${ }^{1}$ \\ ${ }^{1}$ Kazan State Agrarian University, Russia; \\ ${ }^{2}$ Kazan National Research Technical University named after A. N. Tupolev, Russia \\ drgali@mail.ru,fts-kgau@mail.ru, rail-1312@mail.ru
}

\begin{abstract}
Agricultural production is connected with machine technologies of cultivation of agricultural crops. Tractors are operated under certain changing conditions, which are determined by the operation technology, organizational and climatic conditions, and technical operation conditions. The concept is introduced as a complex, dimensionless indicator that determines the conditions of functioning of tractors in agricultural production - the level of operation of tractors. Indicator of the level of operation of tractors reflects the state of their operation on the farm, which determines the degree of implementation of technical operation of equipment and the share of the labor-intensive process in the total volume of planned work for the upcoming period. Theoretically, this indicator can vary from 0 to 1 . When equal to 1 , the state of operation of the tractor is characterized as the best in terms of resource consumption, that is, all measures to maintain the tractor in working condition meet the requirements of GOST, and the tractor performs only work with minimal resistivity. If equal to 0 , resource consumption of the tractor is maximum, i.e. the technical operation of the tractor is not performed and the tractor performs work with the maximum resistivity. The regularities of changes in the unit costs for eliminating failures and downtime depending on the level of operation of tractors are obtained. The article deals with the issues of optimizing the level of operation of tractors, presents a method for optimizing this indicator and provides a calculation on the example of farms in the Republic of Tatarstan.
\end{abstract}

Keywords: optimization, operating level, operating conditions, resource consumption, increased efficiency, generalized factors, determining factors, unit costs.

\section{Introduction}

The current stage of development of agricultural production is associated with market relations. In turn, market relations are characterized by crisis situations, especially at the beginning of the formation of a comprehensive mechanization of the activities of enterprises of the agro-industrial complex with domestic equipment [1-3]. In a situation where prices for new tractors are rising, and the needs of agricultural production are far from being met, the solution is to increase the efficiency of their use, which will reduce the cost of agricultural products and increase competitiveness [4;5]. Improving the efficiency of tractor operation is directly related to the assessment of the conditions of their functioning in agricultural production and the development of measures to improve it. The operating conditions of machinery are evaluated by a complex dimensionless indicator - the level of operation of tractors [6-8].

The state of technical operation of tractors and the percentage of tractor involvement in various types of agricultural work, which is characterized by different resistivity of aggregates, determines the amount of the resource consumption of aggregates and equipment systems. Resource consumption is the amount of reduction in the remaining resource when performing a certain amount of work $[9 ; 10]$.

The level of operation of the tractor $\left(Y_{o}\right)$ can be determined: for the past period, in order to determine the trend in resource consumption of tractor systems and units; for the planned period, in order to develop measures to increase the levels of factors of technical operation of tractors and the formation of the nomenclature of agricultural work. At the same time, the optimal values of resource consumption of tractor systems and aggregates are justified $[11 ; 12]$.

Improving the efficiency of operation of tractors in various conditions of their use is based on the establishment of patterns of changes in indicators of reliability of tractors from the level of operation, taking into account the state of technology. In this regard, the aim of the study is to optimize the level of operation of tractors.

\section{Materials and methods}

Optimization of the level of operation of tractors consists in carrying out measures to optimize the level of their technical operation and offer various options for differentiating agricultural work by tractors [13].

Since the magnitude of the weights of determining and generalized factors is influenced by production and climatic conditions, measures to optimize the level of technical operation consist in 
determining the optimal level value and identifying all the determining factors that have the maximum efficiency coefficients for their implementation groups, ensuring a significant increase in the level of operation. If we increase the levels of these factors to 1 , the value of the final result should provide the optimal level.

Improving the efficiency of tractor operation in enterprises is associated with optimizing the level of technical operation of tractors according to the criterion of minimum total unit costs for repairs, costs from downtime and costs necessary to improve the level of technical operation. To do this, it is necessary to determine the dependence of changes in costs on downtime, on eliminating failures and on improving the technical operation of tractors on the level of technical operation. In this regard, experimental studies were conducted.

Eight farms of the Republic of Tatarstan participated in the experimental studies. In each farm, the levels of technical operation of tractors were determined, according to the developed methodology [11]. Using the accounting data, we obtained the values of costs from tractor downtime and for eliminating their failures. The reliability of the dependencies was determined by the correlation coefficient $(R)$ and its error $\left(m_{R}\right)$ [14], according to which, if the condition $R>3 \cdot m_{R}$ is met, the dependence can be considered reliable.

\section{Results and discussion}

To do this, we need to determine the share of unit costs that depends on the level of technical operation. At the same time, it was assumed that the share of unit costs changes in proportion to the level of technical operation of tractors.

Since the sum of the weights of generalized factors that determine the level of technical operation of tractors is 0.69 [11], the share of unit costs for eliminating failures and downtime in the total volume is 0.69 . Therefore, the objective function of optimizing the level of technical operation of tractors is as follows:

$$
C_{t o}+D_{c} \cdot\left(C_{d}+C_{t}\right) \rightarrow \min .
$$

where $C_{t o}-$ unit costs for improving the level of technical operation of tractors, RUB· hour ${ }^{-1}$; $D_{c}$ - share of unit costs for elimination of failures and downtime, depending on the level of technical operation of tractors in the total volume;

$C_{d}$ - unit costs from downtime, RUB $\cdot$ hour $^{-1}$;

$C_{t}-$ unit costs for troubleshooting failures RUB $\cdot$ hour $^{-1}$.

The unit cost of downtime is determined by the formula:

$$
\begin{gathered}
C_{d}=133.4-273.2 \cdot Y_{o}+144.1 \cdot Y_{o}^{2} . \\
\left(R_{d}=0.71, m_{R d}=0.15\right)
\end{gathered}
$$

The specific cost of eliminating failures is determined by the formula:

$$
\begin{gathered}
C_{t}=121-235.5 \cdot Y_{o}+125.1 \cdot Y_{o}^{2} . \\
\left(R_{t}=0.68, m_{R t}=0.21\right)
\end{gathered}
$$

The unit cost of improving the level of technical operation of tractors is determined from the following expression:

$$
C_{t o}=\frac{Y_{k} \cdot C_{e} \cdot \alpha}{W_{y}},
$$

where $Y_{k}-$ level of determining factors, the implementation of which depends on additional capital investments;

$C_{e}-$ cost of the tractor engine, RUB;

$\alpha-$ standard of investment in agriculture;

$W_{y}$ - annual operating time of the tractor, corresponding to the level of operation. follows:

The dependence of changes in the annual operating time on the level of operation of tractors is as 


$$
\begin{gathered}
W_{y}=5712.48 \cdot y_{o}-1421.32-3064.3 \cdot y_{o}^{2} . \\
\left(R_{y}=0.65, m_{R y}=0.17\right)
\end{gathered}
$$

The level of determining factors, the implementation of which depends on additional capital investments, is determined by the formula:

$$
Y_{k}=D_{s f} \cdot Y_{o}
$$

where $D_{s f}-$ share of factors that require additional capital investment to increase.

With the above in mind, formula (4) will take the following form:

$$
C_{t o}=\frac{D_{s f} \cdot Y_{o} \cdot C_{e} \cdot \alpha}{W_{y}} .
$$

However, the task is to increase the factors of technical operation only. In [11], the factors are divided into 3 groups of implementation: organizational measures; improvement of labor discipline and factors that require additional capital investment. Factors that require additional capital investment include: location of maintenance; availability of equipment for maintenance; location of running-in; location of repairs; availability of mobile repair facilities; storage of fuel and lubricants; fuel filtration during refueling. In this regard, it was necessary to determine the share of 7 factors in the total volume of factors of technical operation of tractors. At the same time, it was assumed that the factors that require additional capital investments to increase change in proportion to the level of technical operation of tractors. To determine the proportion of factors that require additional capital investment, the level of technical operation should be equated to the nominal value. Further, calculations will be made to determine the share of factors that require additional capital investments to increase:

$$
Y_{f k}=\sum_{i=7}^{7} \varphi_{i j}^{k} \cdot z_{i j}^{k} \cdot k_{j}^{k}
$$

where $Y_{f k}-$ level of factors that require additional capital investment to increase;

$\varphi_{i j}{ }^{k}, z_{i j}{ }^{k}$ - accordingly, the level and weight of the $i$-th determining factor included in the $j$-th generalized factor, the increase of which requires additional capital investment; $k_{j}$ - weight of the $j$-th generalized factor.

Substituting the necessary values in formula (8), we obtain the level of factors that require additional capital investment to increase.

$$
Y_{f k}=1 \cdot 0.45 \cdot 0.24+1 \cdot 0.29 \cdot 0.24+1 \cdot 0.43 \cdot 0.18+1 \cdot 0.41 \cdot 0.12+1 \cdot 0.28 \cdot 0.12+1 \cdot 0.38 \cdot 0.09+1 \cdot 0.07 \cdot 0.08=0.38
$$

Therefore, for farms in the Republic of Tatarstan the level of factors that require additional capital investment is 0.38 .

$$
D_{s f}=\frac{Y_{f k} \cdot 100}{Y_{t o=1}}
$$

where $Y_{t o=1}-$ level of technical operation is equal to the nominal (0.69) [11].

$$
D_{f k}=\frac{0.38 \cdot 100}{0.69}=0.55 \text {. }
$$

Thus, given the formulas (2), (3), (6), (7) the target function will look like:

$$
C_{t o}=\frac{0.55 \cdot Y_{o} \cdot \alpha \cdot C_{c}}{5712.48 \cdot Y_{o}-1421.32-3064.3 \cdot Y_{o}^{2}}+175.5-282 \cdot Y_{o}+185.7 \cdot Y_{o}^{2} \rightarrow \min .
$$

where $Y_{o}$ - level of operation of tractors;

$C_{c}$ - unit costs for increasing the level of technical operation, RUB $\cdot$ hour $^{-1}$;

$\alpha$ - coefficient of efficiency of additional capital investments.

The objective function (9) is presented in Figure 3. 


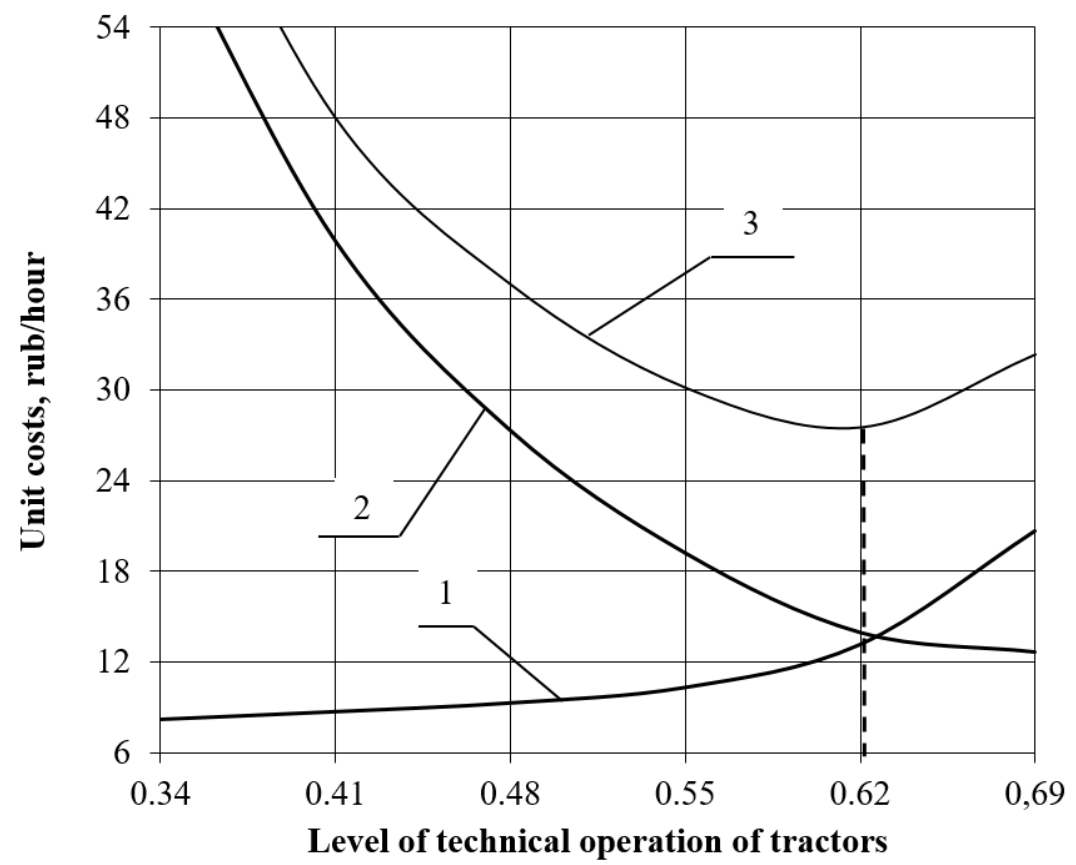

Fig. 1. Schedule for optimizing the level of technical operation of MTZ-80 and MTZ-82 tractors: 1 - unit costs for increasing the level of technical operation; 2 - share of unit costs from downtime and failures accounted for by factors of technical operation; 3 - total costs

The figure shows that the optimal level of technical operation of tractors for farms in the Republic of Tatarstan is 0.62 . In order to increase the level of technical operation to the optimal value, the factors that have the maximum effect were identified. We also determined the optimal level of differentiation of agricultural work by tractors for the planned period, for farms in the Republic of Tatarstan it is 0.24 [11]. Thus, the optimal value of the level of operation of tractors $\left(Y_{o}\right)$ will be equal to 0.86 .

The obtained optimal value of the level of operation of tractors allows to calculate the economically feasible terms of repairs and maintenance of equipment. As a result of mathematical processing of the data obtained during the experimental studies, the optimal values of the total output before the first $\left(T_{1}\right)$, second $\left(T_{2}\right)$ repairs and before the decommissioning of tractors $\left(T_{d}\right)$ were obtained, which are presented in the form of dependencies:

$$
T_{1}=17871.6 \cdot Y_{o}-3467.5-8607.6 \cdot Y_{o}^{2},
$$

in this case, the correlation coefficient and the error of the correlation coefficient, respectively $R_{2}=0.68, m_{2}=0.21[14]$.

$$
T_{2}=13728,2-2812,57 \cdot Y_{o}^{-1,49},
$$

in this case $R_{2}=0.71, m_{2}=0.15$

$$
T_{d}=41217,35 \cdot Y_{o}-7058,8-19521,4 \cdot Y_{o}^{2} .
$$

in this case $R_{d}=0.63, m_{d}=0.18$

Using the obtained dependencies $(11,12,13)$, the optimal terms of repair and service of tractors were determined. As a result of increasing the level of operation of tractors from the actual value to the optimal one, it is expected to increase the time to repair periods and the service life of equipment by $25 \%$.

\section{Conclusions}

1. Determining the optimal level of technical operation of tractors in agricultural production is necessary for planning the costs of their maintenance during the entire service life of the equipment;

2. Increasing the level of technical operation of tractors depends on additional capital investment and determines the cost of eliminating the consequences of failures and downtime during repairs;

3. A method for determining the optimal level of technical operation of tractors in agricultural production is developed and calculations are presented on the example of farms in the Republic of 
Tatarstan. From this, it can see that for the considered zone, the optimal value of the level of technical operation of tractors is 0.62 , and taking into account the level of differentiation of agricultural work by tractors for the planned period $(0.24)$, the level of operation of tractors is 0.86 ;

4. This means that it is not advisable to bring the level of operation of tractors to 1 , since the cost of maintaining tractors will be greater than the effect of reducing the cost of eliminating failures and downtime;

5. For the optimal value of the level of operation of tractors, the appropriate terms of repair and service of tractors are calculated. It is revealed that with an increase in the level of operation of tractors from the actual to the optimal value, the terms before repairs and before write-off will increase by $25 \%$.

\section{References}

[1] Dmitriev A., Ziganshin B., Khaliullin D., Aleshkin A. Study of efficiency of peeling machine with variable deck// Engineering for rural development. 2020. pp. 1053-1058.

[2] Yarullin F., Valiev A., Mukhamadyarov F., Ziganshin B. Determination of energy characteristics of conical rotary working tool for tillage // Engineering for rural development. 2020. pp. 1069-1075.

[3] Alexandr Belinsky, Bulat Ziganshin, Ayrat Valiev, Damir Haliullin, Ilgiz Galiev. Theoretical investigation of increasing efficiency of combine harvester operation on slopes // 18th International Scientific Conference Engineering for rural development Proceedings, Volume 18 May 22-24, 2019 pp. 206-213

[4] Khafizov C.A., Khafizov R.N., Nurmiev A.A., Galiev I.G. Optimization of main parameters of tractor and unit for plowing soil, taking into account their influence on yield of grain crops //19th International Scientific Conference Engineering for rural development Proceedings, Volume 18 May 22-24, 2020 pp.585-590

[5] Nuriev L.M., Yakhin S.M., Aliakberov I.I., Galiev I.G., Sinitsky S.S. Kinematics and parameters for spiral-helical machinery unit used for secondary tillage // International Conference on Technological Solutions and Instrumentation for Agribusiness: Earth and Environmental Science Volume 488, Issue 1, Stavropol; Russian Federation, 2020.

[6] Valiev A., Mukhametshin I., Muhamadyarov F., Yarullin F., Pikmullin G. Theoretical substantiation of parameters of rotary subsoil loosener. 18th International Scientific Conference Engineering For Rural Development Proceedings, Volume 18 May 22-24/Latvia University of Life Sciences and Technologies Faculty of Engineering, Jelgava, 2019, pp. 312-318.

[7] Mukhametshin I., Valiev A., Muhamadyarov F., Kalimullin M., Yarullin F. Kinematic analysis of conical rotary subsoil loosener for tillage. 19th International Scientific Conference Engineering For Rural Development Proceedings, Volume 19 May 20-22, 2020/Latvia University of Life Sciences and Technologies Faculty of Engineering, Jelgava, 2020 - pp. 1946-1952.

[8] Egorov N., Khaliullin F., Khaliullina Z., Zimina L. Adaptive support for power units of machinetractor unit // 19th international scientific conference. Engineering for rural development. -Jelgava: 2020. pp. 1737-1742.

[9] Nurmiev A., Khafizov C., Khafizov R., Ziganshin B. Optimization of main parameters of tractor working with soil-processing implement //17th International Scientific Conference Engineering for rural development Proceedings, Volume 17 May 23-25, 2018 pp.161-167.

[10] Khaliullin F., Akhmetzyanov R., Arslanov F., Korepanov Yu. Method for determining remaining life of engine by dynamic characteristics //19th international scientific conference. Engineering for rural development. -Jelgava: 2020. pp. 1096-1101.

[11] Galiev I.G., Khafizov K.A., Khusainov R.K., Faskhutdinov M.Kh. Ensuring possibility of functioning of tractors in agricultural production taking into account residual resources of their units and systems //19th International Scientific Conference Engineering for rural development Proceedings, Volume 18 May 22-24, 2020 pp. 48-53

[12] Fortuna V.I., Mironyuk S.K. Technology of mechanized agricultural works. - M.: Agropromizdat, 1986.-304 p. (Textbooks and textbook. AIDS for agricultural technical schools).

[13] Mikhlin V.M. Managing the reliability of agricultural machinery. -M.: Kolos, 1984. 335 p.

[14] Krastin O.P. Methods of analysis of regressions and correlations. - Riga: CSU SM of the Latvian SSR, 1970,347 p. 5. 